\title{
Ion-Pair Formation of a Copper(II)-Ammine Complex with an Anionic Surfactant and the Recovery of Copper(II) from Ammonia Medium by the Surfactant-Gel Extraction Method
}

\author{
Takayuki NAKaI,* Yoshiko MuraKaMI,* Yoshiaki SASAKI,* Isamu FuJIWARA,** and \\ Shoji TAgaShIRA*ं \\ *Department of Chemistry, Faculty of Science, Yamaguchi University, \\ 1677-1 Yoshida, Yamaguchi 753-8512, Japan \\ **The Center for Waste Water Treatment, Yamaguchi University, 1677-1 Yoshida, Yamaguchi 753-8511, Japan
}

\begin{abstract}
The extraction and separation of copper(II), zinc(II), cobalt(II), and cadmium(II) were investigated. Both copper(II) and zinc(II) formed ammine-complexes, while cadmium(II) and cobalt(II) formed hydroxide precipitates in an ammonia medium. By the addition of sodium dodecylsulfate (SDS), a copper(II) complex formed an ion-pair (copper-ammineDS), which was extracted into the SDS phase. However, a zinc(II) complex did not form an ion-pair, and was soluble in water. Copper(II) ion was recovered by stripping (back-extraction) after the addition of hydrochloric acid. This method was applied to the separation of copper(II) in a brass alloy.
\end{abstract}

(Received August 27, 2003; Accepted October 27, 2003)

\section{Introduction}

Recently, there has been a general concern for decreasing the discharge or disposal of effluents containing hazardous heavy metals. Such effluents often contain valuable metals; thus, there is an economic interest in their recovery for recycling. There are many methods for the recovery of metals in effluents. Among these methods, solvent extraction ${ }^{1,2}$ is one of the most attractive because it offers various alternatives for metal separation and concentration in a multi-element system, including selective extraction. However, organic solvents, such as chloroform or benzene, are volatile and noxious; ${ }^{3}$ therefore, the conventional solvent extraction methods are not desirable from the viewpoint of environmental preservation and their harmful influence on human health.

Interest has been shown in the separation of metal ions by an extraction and/or adsorption method that uses a surfactant and a polymer electrolyte of a solid or a liquid as the extraction medium. ${ }^{4-10}$ Sodium dodecylsulfate (SDS), which has low toxicity and is easily biodegraded, was used as the extraction medium. The purpose of this study is the extraction of a copper(II) ammine-complex with SDS after ion-pair formation. Ammonia is an important industrial substance and has a large number of uses. It is used as a leaching reagent for copper from chalcocite or chalcopyrite in the mining industry ${ }^{11}$ and for the recovery of copper from spent etching agents. ${ }^{12}$ There are few reports concerning the extraction of copper(II) as an amminecomplex. The ammine-complex undergoes a ligand-exchange reaction using a hydrophobic reagent, such as LIX-973N,,$^{13}$ and solvent extraction is then carried out. ${ }^{13-15}$ In the present study, SDS plays the role of a pairing ion for an ammine-complex and medium; the composition of the ion-pair is $\mathrm{Cu}\left(\mathrm{NH}_{3}\right)_{4}(\mathrm{DS})_{2}$. The

$\doteqdot$ To whom correspondence should be addressed.

E-mail: taga@yamaguchi-u.ac.jp ion-pair of copper(II) was directly extracted into the SDS phase, and the mutual separation of metals was performed.

\section{Experimental}

\section{Reagents}

First, $0.10 \mathrm{~mol} \mathrm{dm}^{-3}$ stock solutions of metal ions were separately prepared by dissolving appropriate amounts of copper(II) nitrate (Kishida Chemicals, Osaka), zinc(II) chloride (Kishida Chemicals, Osaka), cobalt(II) nitrate (Katayama Chemicals, Osaka) or cadmium(II) nitrate (Katayama

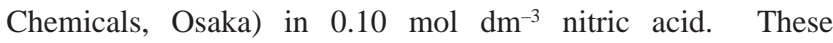
concentrations were titrimetrically standardized with EDTA. The commercial product of ammonia water $(28 \%$, Kanto Chemicals, Tokyo) was used as received. Then, $0.70 \mathrm{~mol} \mathrm{dm}^{-3}$ sodium dodecylsulfate (Wako Pure Chemicals, Tokyo) and 3.0 mol dm${ }^{-3}$ sodium chloride (Kanto Chemicals, Tokyo) solutions were prepared by dissolving these reagents in water. All chemicals were of analytical grade and were dissolved in deionized water.

\section{Apparatus}

An absorbance measurement was performed with a Shimadzu UV-265 spectrophotometer using a quartz cell of $1.0 \mathrm{~cm}$ path length. The metal concentration was determined using a Shimadzu AA-625-11 flame atomic absorption spectrometer (AAS) or a Varian LIBERTY SERIES II inductively coupled plasma atomic emission spectrometer (ICP-AES). All pH measurements were performed with a Horiba M-7 pH meter in combination with a glass electrode. A Hitachi Himac CF7D2 centrifuge was used for phase separation.

Separation of copper(II) and zinc(II) by a surfactant-extraction method

A solution containing copper(II) and zinc(II) was transferred 


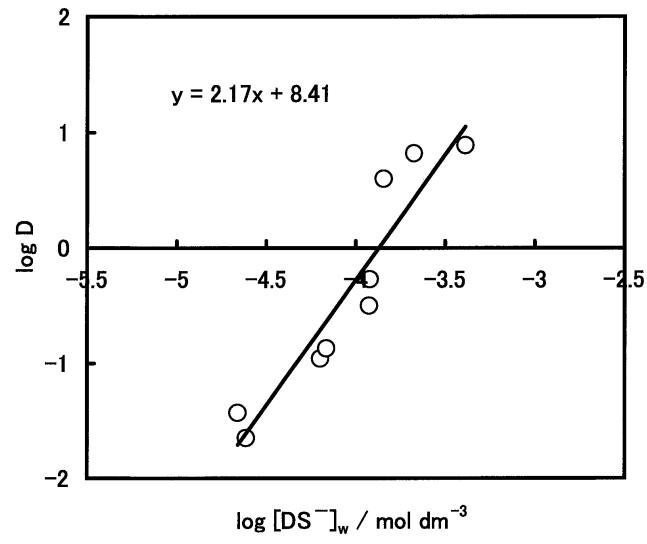

Fig. 1 Plot of $\log D$ against $\log \left[\mathrm{DS}^{-}\right]_{\mathrm{w}}$ for the ion-pair of copperammine-DS. $\left[\mathrm{Cu}^{2+}\right]=1.0 \times 10^{-3} \mathrm{~mol} \mathrm{dm}^{-3},\left[\mathrm{NH}_{3}\right]=0.40 \mathrm{~mol} \mathrm{dm}^{-3}$.

to a $10 \mathrm{~cm}^{3}$ centrifuge tube with a graduation line. After successively adding $0.30 \mathrm{~cm}^{3}$ of ammonia water and $1.0 \mathrm{~cm}^{3}$ of SDS, the solution was diluted to $9.0 \mathrm{~cm}^{3}$ with water. The solution was shaken, and $1.0 \mathrm{~cm}^{3}$ of sodium chloride was then added as a salting-out reagent. After cooling the solution in an ice-water bath and centrifuging $\left(0^{\circ} \mathrm{C}, 5000 \mathrm{rpm}, 10 \mathrm{~min}\right)$, the ion-pair of copper(II) was extracted into the SDS phase, and the zinc(II) ammine-complex remained in the aqueous phase. A 5.0 $\mathrm{cm}^{3}$ portion of $1.0 \mathrm{~mol} \mathrm{dm}{ }^{-3}$ hydrochloric acid was added to the SDS phase located at the bottom of tube and was diluted to 9.0 $\mathrm{cm}^{3}$ with water. By adding $1.0 \mathrm{~cm}^{3}$ of sodium chloride solution, cooling and centrifuging, the copper(II) ion was back-extracted into the aqueous phase. After the separation of phases, the copper was quantitatively recovered from the aqueous phase as copper(II) hydroxide by the addition of sodium hydroxide.

\section{Results and Discussion}

\section{The formation of ion-pair}

Because it was difficult to directly determine the composition of the ion-pair in SDS medium, a conventional extraction method was used. The overall formation constants of $\left[\mathrm{Cu}\left(\mathrm{NH}_{3}\right)_{4}\right]^{2+}$ and $\left[\mathrm{Zn}\left(\mathrm{NH}_{3}\right)_{4}\right]^{2+}$ are 12.5 and 9.3 for $\log \beta_{4 .}{ }^{16}$ Therefore, most of the copper(II) and zinc(II) formed an ammine-complex in $0.40 \mathrm{~mol} \mathrm{dm}^{-3}$ ammonia media. By the addition of SDS, the solution involving the copper(II) amminecomplex became turbid and formed a precipitate of the ion-pair (copper-ammine-DS; $\mathrm{DS}^{-}$corresponds to the dodecylsulfate anion). The composition of this ion-pair was determined by a solvent-extraction method. From a preliminary experiment, $n$ pentyl alcohol was chosen as the extracting solvent.

The pairing ion of SDS distributed itself between the two phases, assuming that dodecylsulfate completely dissociates in the aqueous phase, and exists as sodium or ammonium salt in the organic phase. The distribution ratio, $\left(D_{\mathrm{SDS}}\right)$, is defined as

$$
D_{\mathrm{SDS}}=[\mathrm{SDS}]_{\mathrm{o}} /\left[\mathrm{DS}^{-}\right]_{\mathrm{w}},
$$

where the subscripts $\mathrm{w}$ and o denote the aqueous phase and organic phase, respectively. The total SDS concentration is represented as

$$
[\mathrm{SDS}]_{\mathrm{t}}=\left[\mathrm{DS}^{-}\right]_{\mathrm{w}}+[\mathrm{SDS}]_{\mathrm{o}}
$$

We obtained the following equation from Eqs. (1) and (2):

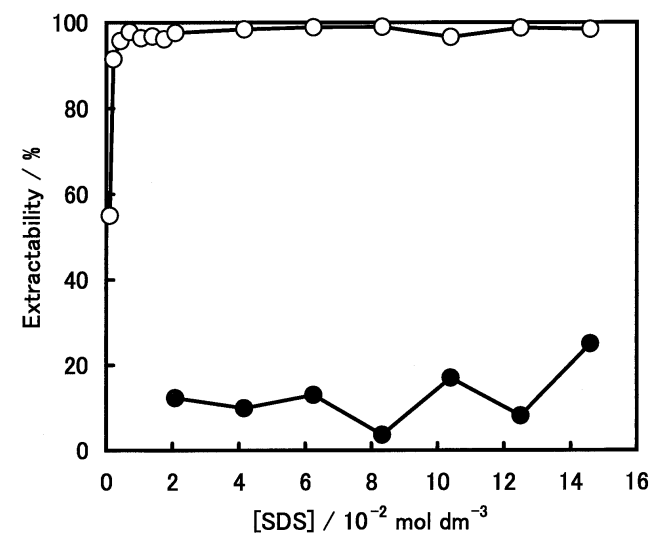

Fig. 2 Effect of the SDS concentration on the extractability of copper(II) and zinc(II). $\circ, \mathrm{Cu}(\mathrm{II}) ; \bullet, \mathrm{Zn}(\mathrm{II}) . \quad\left[\mathrm{Cu}^{2+}\right]=1.0 \times 10^{-3}$ $\mathrm{mol} \mathrm{dm}{ }^{-3},\left[\mathrm{Zn}^{2+}\right]=1.0 \times 10^{-3} \mathrm{~mol} \mathrm{dm}^{-3},\left[\mathrm{NH}_{3}\right]=0.40 \mathrm{~mol} \mathrm{dm}^{-3}$, $[\mathrm{NaCl}]=0.30 \mathrm{~mol} \mathrm{dm}^{-3}$.

$$
[\mathrm{SDS}]_{\mathrm{t}}=\left(D_{\mathrm{SDS}}+1\right)\left[\mathrm{DS}^{-}\right]_{\mathrm{w}} .
$$

The concentration of DS- in the aqueous phase was measured by the ethylviolet absorptiometric method, ${ }^{17}$ and the obtained $D_{\mathrm{SDS}}$ was 10.5. The extraction constant of the ion-pair is

$$
K_{\mathrm{ex}}=\left[\mathrm{Cu}\left(\mathrm{NH}_{3}\right)_{4}(\mathrm{DS})_{n}\right]_{\mathrm{o}} /\left(\left[\mathrm{Cu}\left(\mathrm{NH}_{3}\right)_{4}{ }^{2+}\right]_{\mathrm{w}}\left[\mathrm{DS}^{-}\right]^{n}{ }_{\mathrm{w}}\right) .
$$

Assuming that the ion-pair concentration is negligibly small in the aqueous phase, the distribution ratio, $(D)$, is defined as

$$
D=\left[\mathrm{Cu}\left(\mathrm{NH}_{3}\right)_{4}(\mathrm{DS})_{n}\right]_{\mathrm{o}} /\left[\mathrm{Cu}\left(\mathrm{NH}_{3}\right)_{4}{ }^{2+}\right]_{\mathrm{w}} .
$$

This equation is substituted in Eq. (4), giving

$$
\log D=n \log \left[\mathrm{DS}^{-}\right]_{\mathrm{w}}+\log K_{\mathrm{ex}} \text {. }
$$

As can be seen from Fig. 1, the slope of the straight line was set at about 2. The composition of the ion-pair was $\mathrm{Cu}\left(\mathrm{NH}_{3}\right)_{4}(\mathrm{DS})_{2}$, and the extraction constant $\left(K_{\mathrm{ex}}\right)$ was $2.57 \times 10^{8}$.

The structure of the ammine-complexes may influence the formation or stability of the ion-pairs. It is well-known that zinc(II) forms a tetrahedral complex with ammonia, but the copper(II) ammine-complex has a square-planar geometry. ${ }^{18}$ Anionic DS- easily approached a copper(II) ammine-complex from the horizontal direction where a water molecule or ammonia is weakly bonded. On the other hand, it is difficult to approach to the zinc(II) complex, and an ion-pair is not formed.

\section{Separation of metals by surfactant-gel extraction}

The effect of the sodium chloride concentration on the extractabilities of cooper(II) and zinc(II) was studied from 0 to $0.62 \mathrm{~mol} \mathrm{dm}^{-3}$, and a high extraction efficiency was obtained over $6.8 \times 10^{-2} \mathrm{~mol} \mathrm{dm}^{-3}$. A similar effect of surfactant SDS was also investigated in the concentration range from $1.0 \times 10^{-3}$ to $0.15 \mathrm{~mol} \mathrm{dm}^{-3}$. The obtained results are shown in Fig. 2 . Above $4.2 \times 10^{-3} \mathrm{~mol} \mathrm{dm}^{-3}$, copper(II) was quantitatively extracted into the SDS phase and about $15 \%$ zinc(II) was extracted. A preliminary experiment gave a result in which $10-$ $20 \%$ of cationic metal ions, such as copper(II) and zinc(II), transferred to the SDS phase due to an electrostatic interaction in the absence of ammonia. Because the removal of zinc(II) was not complete in a single extraction, a double extraction was recommended for removal. The ammonia concentration was 


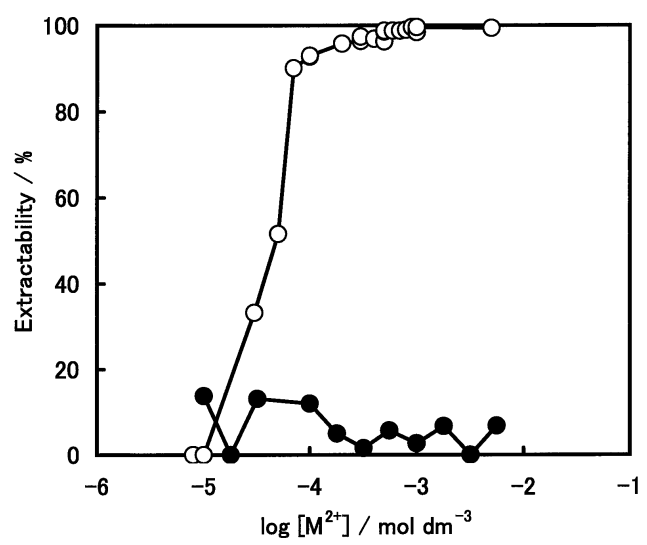

Fig. 3 Influence of the metal concentration on the extractability of copper(II) and zinc(II). $\circ, \mathrm{Cu}(\mathrm{II}) ; \bullet, \mathrm{Zn}(\mathrm{II}) . \quad\left[\mathrm{NH}_{3}\right]=0.40 \mathrm{~mol}$ $\mathrm{dm}^{-3},[\mathrm{SDS}]=7.0 \times 10^{-2} \mathrm{~mol} \mathrm{dm}^{-3},[\mathrm{NaCl}]=0.30 \mathrm{~mol} \mathrm{dm}^{-3}$.

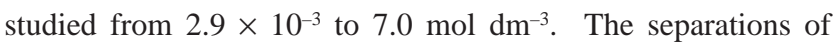
copper(II) and zinc(II) were achieved above $3.8 \times 10^{-2} \mathrm{~mol}$ $\mathrm{dm}^{-3}$.

Under the optimal separation conditions, the metal concentration for the extractability was studied. The results are shown in Fig. 3. More than $95 \%$ copper(II) was extracted above the initial concentration of $2.0 \times 10^{-4} \mathrm{~mol} \mathrm{dm}^{-3}$. The extractability of zinc(II) was less than $15 \%$. Cobalt(II) and cadmium(II) form hydroxides, even in ammonia medium, because the formation constants of $\left[\mathrm{Co}\left(\mathrm{NH}_{3}\right)_{4}\right]^{2+}$ and $\left[\mathrm{Cd}\left(\mathrm{NH}_{3}\right)_{4}\right]^{2+}$ were 5.9 and 7.0 for $\log \beta_{4 .}{ }^{16}$ These values are smaller than that of copper(II). Hence, cobalt(II) and cadmium(II) could be removed by filtrating before the addition of SDS.

\section{Stripping of copper(II)}

The stripping of copper(II) into an aqueous phase was based on the dissociation of the ammine-complex by adding an acid The decomposition of the ion-pair is

$$
\mathrm{Cu}\left(\mathrm{NH}_{3}\right)_{4}(\mathrm{DS})_{2}+4 \mathrm{H}^{+} \longrightarrow \mathrm{Cu}^{2+}+4 \mathrm{NH}_{4}^{+}+2 \mathrm{DS}^{-} .
$$

The effect of the hydrochloric acid concentration on the back-

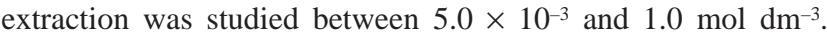
The recovery of copper(II) was quantitative above $5.0 \times 10^{-2}$ mol $\mathrm{dm}^{-3}$ of the hydrochloric acid concentration, and was performed with $0.50 \mathrm{~mol} \mathrm{dm}^{-3}$ hydrochloric acid.

\section{Separation of copper and zinc in brass alloy}

Brass is a popular alloy for industrial and household use. A pretreatment of the sample was carried out as follows. A $1.47 \mathrm{~g}$ sample of brass $^{19}$ (SMB electric clamp, Radiall, France) was decomposed in a small amount of concentrated nitric acid. The solution was heated and evaporated to dryness. The residue was dissolved in $3.0 \mathrm{~cm}^{3}$ of concentrated nitric acid and diluted with water to $200 \mathrm{~cm}^{3}$. The composition of brass was determined by ICP-AES. The main components of this sample were $57.1 \%$ copper and $37.0 \%$ zinc, and a small amount of lead $(3.0 \%)$, nickel $(0.5 \%)$ and iron $(<0.1 \%)$ were present. The sample solution was filtered before SDS extraction. Table 1 gives the results of the separation of copper and zinc using this solution. By the double-extraction procedure, about $99 \%$ copper could be separated into the SDS phase and $98 \%$ zinc remained in the aqueous phase. Also, the stripped copper in the aqueous phase
Table 1 Separation of copper and zinc in brass alloy

\begin{tabular}{ccccccc}
\hline \multirow{2}{*}{ Metal } & \multicolumn{2}{c}{ Extraction ${ }^{\mathrm{a}} \%$} & & \multicolumn{2}{c}{ Back-extraction ${ }^{\mathrm{a}}, \%$} \\
\cline { 2 - 3 } \cline { 5 - 6 } & Single & Double & & Single & Single + washing \\
\hline \multirow{2}{*}{$\mathrm{Cu}$} & $98.4 \pm 1.5^{\mathrm{b}}$ & $98.8 \pm 0.2^{\mathrm{b}}$ & & $96.4 \pm 0.5^{\mathrm{c}}$ & $98.8 \pm 0.5^{\mathrm{c}}$ \\
$\mathrm{Zn}$ & $86.5 \pm 5.5^{\mathrm{c}}$ & $97.7 \pm 0.7^{\mathrm{c}}$ & & $2.1 \pm 0.5^{\mathrm{c}}$ & $2.3 \pm 0.7^{\mathrm{c}}$ \\
\hline
\end{tabular}

a. Average $\pm \mathrm{SD}$ (3 samples).

b. SDS phase.

c. Aqueous phase.

was recovered at $98.3 \pm 0.7 \%$ as copper(II) hydroxide by the addition of sodium hydroxide and filtration.

After stripping and washing, the SDS phase did not involve any metals and was available for reuse. The present method may be applied to a pretreatment for environmental metal analysis and can also be used to recycle metals or to remove harmful metals from wastewater.

\section{References}

1. A. K. De, S. M. Khopkar, and R. A. Chalmers, "Solvent Extraction of Metals", 1970, Van Nostrand Reinhold, London, $241-242$

2. S. Nakamura, S. Takei, and K. Akiba, Anal. Sci., 2002, 18, 319.

3. H. Imura, K. Ishimori, and K. Ohashi, Anal. Sci., 2000, 16, 1297

4. J. F. Scamehorn and J. H. Harwell, "Surfactant-Based Separations, Science and Technology", 2000, ACS, Washington, $139-157$.

5. S. A. Kulichenko, V. O. Doroschuk, and S. O. Lelyushok, Talanta, 2003, 59, 767.

6. S. Tagashira, Y. Murakami, M. Yano, and Y. Sasaki, Bull. Chem. Soc. Jpn., 1998, 71, 2137.

7. T. Saitoh, T. Ohyama, K. Takamura, T. Sakurai, T. Kaise, and C. Matsubara, Anal. Sci., 1997, 13, 1.

8. C. Matsubara, Bunseki, 1999, 1, 60.

9. K. Ihara, S. Hasegawa, and K. Naito, Anal. Sci., 2003, 19, 265.

10. J. L. Manzoori and G. Karim-Nezhad, Anal. Sci., 2003, 19 , 579.

11. L. C. Emeles, D. C. Cupertino, S. G. Harris, S. Owens, S. Parsons, R. M. Swart, P. A. Tasker, and D. J. White, J. Chem. Soc., Dalton Trans., 2001, 1239.

12. Y. K. P. Sze and J. C. Wong, Environ. Technol., 1994, 15, 785.

13. F. J. Alguacil, Hydrometallurgy, 1999, 52, 55.

14. G. Kyuchoukov, M. B. Bogacki, and J. Szymanowski, Ind. Eng. Chem. Res., 1998, 37, 4084.

15. F. J. Alguacil and A. Cobo, Sep. Sci. Technol., 1998, 33, 2257.

16. E. Hogfeldt, "Stability Constants of Metal-Ion Complexes", 1982, Pergamon Press, Oxford, 111.

17. S. Motomizu, S. Fujiwara, A. Fujiwara, and K. Toei, Anal. Chem., 1982, 54, 392.

18. T. L. Brown, H. E. LeMay, Jr., and B. E. Bursten, "Chemistry", 8th ed., 2000, Prentice Hall International, New Jersey, 931 - 932.

19. S. Tagashira, I. Fujiwara, K. Ochi, Y. Murakami, and Y. Sasaki, J. Environ. Chem. (Kankyo Kagaku), 2002, 12, 609. 